\title{
Single Atomically Anchored Cobalt on Carbon Quantum Dots as Efficient Photocatalysts for Visible Light-Promoted Oxidation Reactions
}

\author{
Qin Wang, Jin Li, Xianjun Tu, Hongbo Liu, Miao Shu, Rui Si, Calum T. J. Ferguson, Kai. A. I. Zhang, * \\ and Run $\mathrm{Li}^{*}$
}

Cite This: Chem. Mater. 2020, 32, 734-743

Read Online

ACCESS | Lلll Metrics \& More | 回 Article Recommendations ｜ sl Supporting Information

ABSTRACT: Generation of efficient light-induced charge separation inside the photocatalyst is an essential factor for a high catalytic efficiency. The usual immobilization of metal or metal oxide particles on semiconductor photocatalysts offers an uncontrolled assembly of active sites during the reaction. The introduction of single metal atoms on photocatalysts can lead to extremely high atomic utilization and precise active sites. However, this approach is limited because of the lack of suitable photosensitizers for single atom immobilization. Here, we have designed photocatalytic carbon quantum dots with anchoring sites for single cobalt atoms in a defined $\mathrm{Co}-\mathrm{N}_{4}$ structure via facile pyrolysis of vitamin B12. Carbon dots functioned as both light-harvesting antenna and support for the cobalt atom with high atom loadings up to $3.27 \mathrm{wt} \%$. This new photocatalytic material demonstrated enhanced visible light absorption, efficient charge separation,

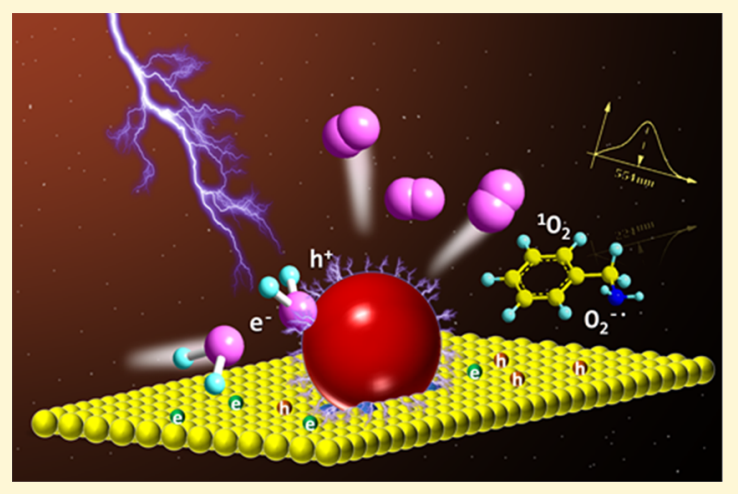
and reduced electrochemical impedance, while single Co atoms acted as the active site with strong oxidative ability. As a result, the photocatalysts showed excellent visible light-promoted photocatalytic efficiency with oxygen evolution rates up to $168 \mu \mathrm{mol} \mathrm{h}{ }^{-1} \mathrm{~g}^{-1}$ via water oxidation, imine formation with high conversion $(\sim 90 \%)$ and selectivity (>99\%), and complete photodegradation of organic dyes.

\section{INTRODUCTION}

The efficiency of photocatalysts can be largely increased by enhancing the efficient light-induced charge separation inside the photocatalyst material. To achieve this, a vast number of catalyst materials and their modification methods have been explored. ${ }^{1-3}$ Recently, carbon quantum dots (CQDs) have emerged as a promising photocatalyst candidate for solar-toenergy conversion, due in part to their ease of preparation, low cost, excellent stability, high quantum yield, nontoxicity, high aqueous affinity, and visible light absorption. ${ }^{4-7}$ Recently, CQDs have been employed for energy-relevant applications as hydrogen evolution ${ }^{8,9}$ or photocatalytic chemical transformations including epoxide ring opening; ${ }^{10}$ reductive dehalogenation; ${ }^{11}$ and the oxidation of amines, ${ }^{12}$ benzyl alcohol ${ }^{13}$ and $1,4-$ dihydro-2,6-dimethylpyridine-3,5-dicarboxylate, ${ }^{14}$ and so forth. However, the study of CQDs for photocatalysis in visible light is still in its infancy, with further improvement in catalytic efficiency required. Therefore, there is an urgent demanded for the design and modification of CQD photocatalysts.

One of the most frequently used modification methods for photocatalysts is the immobilization of metal or metal oxides on their surface. Recent studies report CQDs in combination with other semiconductor materials such as $\mathrm{TiO}_{2}{ }^{15} \mathrm{WO}_{3}{ }^{16}$ and $\mathrm{g}^{-} \mathrm{C}_{3} \mathrm{~N}_{4} \cdot{ }^{17}$ Nevertheless, those methods offer an uncon- trolled assembly of active sides during the reaction. More precise and controlled modification methods of CQDs still need to be investigated.

Single atom catalysts (SACs) have become a new active frontier in heterogeneous catalysis as they produce the highest possible per metal atom efficiency. Furthermore, they can be utilized to produce desired products with excellent selectivity and conversion. ${ }^{18-20}$ Unlike in classical metal catalysis, reducing the metal to single atoms enhances the number of available catalytic sites. Moreover, the intrinsic activity of the coordinated atoms may be enhanced because of alteration of the electronic and energy level structure. For example, single Pt atoms anchored onto the surface of iron oxide $\left(\mathrm{Pt}_{1} / \mathrm{FeO}_{x}\right)$ form a positively charged $\mathrm{Pt}$ atom. This is due to electron transfer from the $\mathrm{Pt}$ center to the $\mathrm{FeO}_{x}$ surface, resulting in extraordinary high efficiency for $\mathrm{CO}$ oxidation by the $\mathrm{Pt}_{1} / \mathrm{FeO}_{x}$ catalyst. ${ }^{21}$ Single $\mathrm{Pd}$ atoms immobilized on $\mathrm{g}-\mathrm{C}_{3} \mathrm{~N}_{4}$ demonstrated a reaction rate of $0.57 \mathrm{mmol}_{\text {product }} \mathrm{min}^{-1} \mathrm{~g}_{\mathrm{cat}}^{-1}$ in a

Received: September 9, 2019

Revised: December 23, 2019

Published: December 26, 2019 
continuous Suzuki coupling reaction, much higher than commercial Pd catalysts. ${ }^{22}$ Further to thermal reactions, SACs have been utilized in electrocatalytic reactions including hydrogen reduction, $\mathrm{CO}_{2}$ reduction, and nitrogen reduction. $^{23,24}$

The utilization of single atoms in visible light photocatalysis is currently a major challenge. This difficulty arises from the need for a host that can act as both a light-harvesting agent and a support for the metal single atom. Currently, host materials mainly focus on $\mathrm{g}-\mathrm{C}_{3} \mathrm{~N}_{4}{ }^{25-28}$ Single $\mathrm{Fe}, \mathrm{Pt}$, and $\mathrm{Co}$ atoms have been anchored onto g- $\mathrm{C}_{3} \mathrm{~N}_{4}$, with improved photocatalytic efficiency for pollutant degradation, ${ }^{25}$ hydrogen evolution, ${ }^{26}$ water splitting, ${ }^{27}$ and $\mathrm{CO}_{2}$ reduction ${ }^{28}$ observed. However, the mass loading of single atoms on $\mathrm{g}^{-} \mathrm{C}_{3} \mathrm{~N}_{4}$ are generally low $(<1 \%)$ and may limit its photocatalytic applications.

Here, we report the design and synthesis of CDQs with surface anchored single Co atoms in $\mathrm{Co}-\mathrm{N}_{4}$ structures with a high atom loading of $3.27 \mathrm{wt} \%$ (Scheme 1). The aim of the

Scheme 1. Illustration of the Single Cobalt Atom Anchored in the Carbon Quantum Dot for Photocatalytic Oxidation Reactions, Such as Oxygen Evolution and Oxidative Coupling of Benzylamines ${ }^{a}$

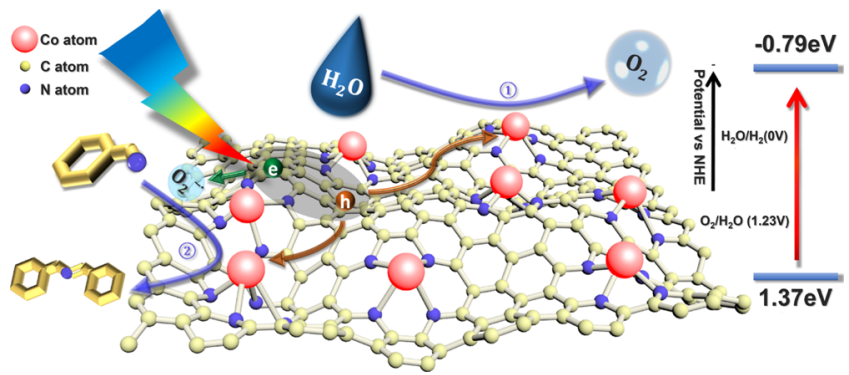

${ }^{a_{T}}$ The photogenerated hole plays an essential role for oxidation reactions. The reduction and oxidation potentials are -0.79 and 1.37 $\mathrm{V}$ versus SCE, respectively.

use of the singly anchored Co atoms was to enhance the lightinduced charge separation and boost charge transport within the materials, where the photogenerated hole species can be concentrated on the single Co atoms as active catalytic sites. CQDs served as both the light-harvesting antenna and support for single Co atoms. To the best of our knowledge, this is the first case for CQD being employed as the host material for SACs. The obtained photocatalyst demonstrated enhanced visible light absorption and charge separation efficiency. The catalytic capacity was investigated via three oxidation reactions, that is, water oxidation, oxidative coupling of aromatic amines, and photodegradation of an organic dye. Catalytic efficiency with an oxygen evolution rate, during water oxidation, of up to $168 \mu \mathrm{mol} \mathrm{h} \mathrm{h}^{-1} \mathrm{~g}^{-1}$ was obtained. Imine synthesis over 15 reactions was demonstrated with conversions and selectivity up to $99 \%$. Rapid degradation of the organic dye rhodamine B (RhB) (conc. $10 \mathrm{mg} / \mathrm{L}$; $<10 \mathrm{~min}$ ) was also observed. Furthermore, the CQD-based photocatalysts anchored with single Co atoms showed high stability in all three oxidation reactions.

\section{RESULTS AND DISCUSSION}

The anchoring of single cobalt atoms on the carbon dot catalyst (CoSAS@CD) was achieved via a facile hydrolysis of cobalt-loaded carbon material in $\mathrm{NaOH}$ solution. The carbon precursor was obtained by pyrolysis of vitamin B12 (VB12) as a convenient approach to synthesize single cobalt atomdecorated carbon material similar to previous reports. ${ }^{29,30}$ Because of its intrinsic advantages, such as atomically dispersed cobalt in the porphyrin framework, high N/C atomic ratios (0.22), and low melting point and carbonization temperature, VB12 has been frequently utilized as the carbonization precursor in previous reports. ${ }^{29-33}$ The thermal stability of VB12 was investigated via thermogravimetric analysis (TGA) analysis where VB12 demonstrated the first weight loss stage $(\sim 5 \%)$ below $100{ }^{\circ} \mathrm{C}$ because of the removal of absorbed water and then underwent a large weight loss stage $(\sim 50 \%)$ between 230 and $450{ }^{\circ} \mathrm{C}$ which was attributed to thermal decomposition and carbonization (Figure S1). According to the TGA result, three different pyrolysis temperature (200, 250 , and $300{ }^{\circ} \mathrm{C}$ ) were tested in CQD preparation. When the temperature was set to be $200{ }^{\circ} \mathrm{C}$, VB12 could stabilize without structure change. When the temperature increased to $300{ }^{\circ} \mathrm{C}, \mathrm{VB} 12$ was over carbonized, and no CQD could be achieved during the $\mathrm{NaOH}$ treatment. Thus, the optimized pyrolysis temperature was $250{ }^{\circ} \mathrm{C}$ where we could get highquality CQD CoSAS@CD with an excellent reaction yield of $28 \%$. To investigate the synergistic cooperation between the single cobalt atom and carbon dot, a number of reference materials were prepared including, acid-treated carbon dot catalysts (CoSAS@CD-acid), a cobalt/carbon dot hybrid material (Co@CD), and a carbon dot using meso-tetra- $p$ tolylprophyrin as the precursor (TTP@CD). In addition, because TTP started to undergo carbonization at $\sim 280{ }^{\circ} \mathrm{C}$, as shown in Figure S1, a lower pyrolysis temperature $\left(350{ }^{\circ} \mathrm{C}\right)$ was also carried out for better comparison, which was named as TTP@CD-350. The detailed synthetic procedures and characterization data are described in the Supporting Information.

The morphology of the carbon dots was investigated using transmission electron microscopy (TEM) (Figures 1 and S2). All the obtained carbon dots were spherical nanocomposites with an average diameter of 9.0, 7.1, 7.6, and $5.3 \mathrm{~nm}$ for CoSAS@CD, CoSAS@CD-acid, Co@CD, and TTP@CD, respectively. The X-ray diffraction (XRD) pattern (Figure S3) of CoSAS@CD, displayed no characteristic peak assignable to cobalt crystal particles or its compounds. This indicates that the cobalt species in CoSAS@CD are either highly dispersed as single atoms or extremely amorphous. The broadened peak at around $22^{\circ}$ was attributed to the (002) phase of the carbon material with a low graphitization degree. In addition, the two peaks around 26 and $42^{\circ}$ in CoSAS@CD-acid were assigned to the (002) and (004) plane of graphite. Carbon dots with the citric acid precursor demonstrated a graphite lattice with a $d$ spacing of $0.35 \mathrm{~nm}$, while with the TTP precursor showed a $d$ spacing of $0.56 \mathrm{~nm}$.

In order to determine the distribution of cobalt in CoSAS@ $\mathrm{CD}$, sub-Ångström-resolution aberration-corrected high-angle annular dark-field scanning TEM (HAADF-STEM) measurement was performed (Figure $1 \mathrm{~b}$ ). The bright dots observed, with a diameter of less than $0.2 \mathrm{~nm}$, may be attributed to individual cobalt atoms. This would indicate that cobalt atoms are dispersed on the carbon dot surface. In addition, the presence of $\mathrm{C}, \mathrm{N}$, and $\mathrm{Co}$ is manifested via the energy dispersive $\mathrm{X}$-ray spectroscopy image which indicates that those elements are uniformly distributed in CoSAS@CD (Figure S4). The height profile of CoSAS@CD is investigated by AFM analysis (Figure S5). A height of less than $2 \mathrm{~nm}$ determined for 


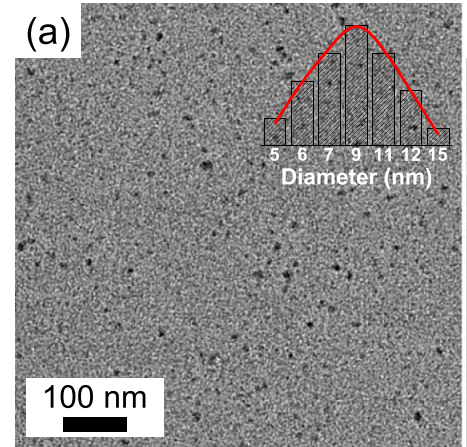

(d)

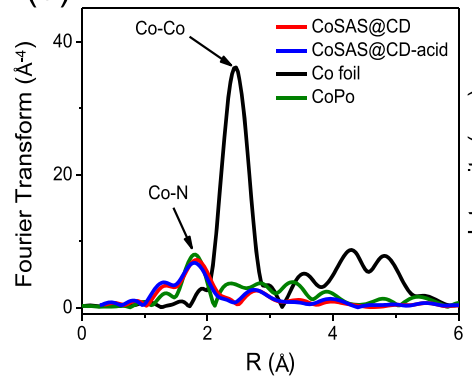

(g)

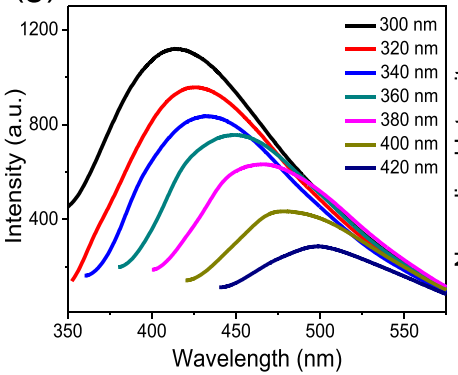

(b)

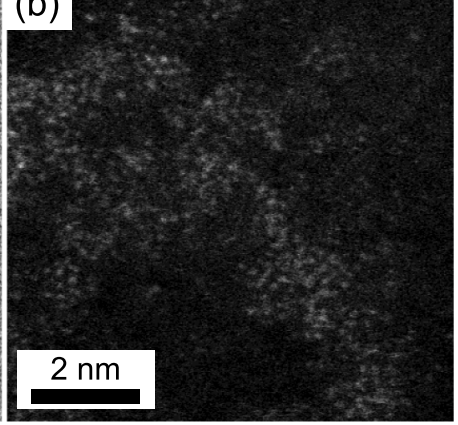

(e)

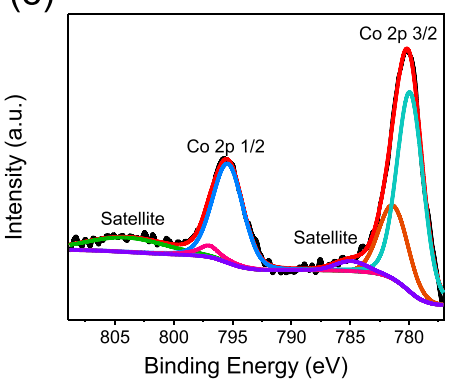

(h)

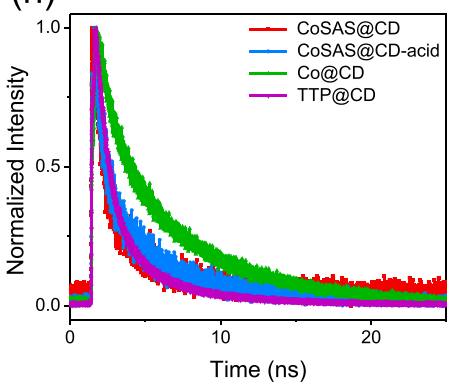

(c)

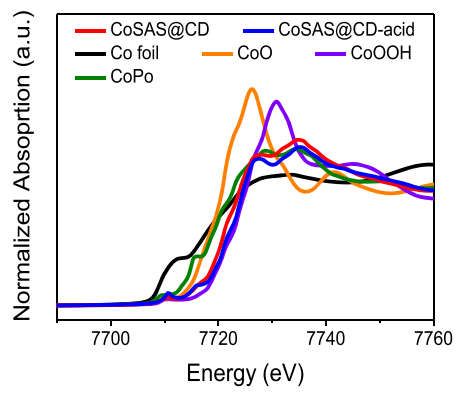

(f)

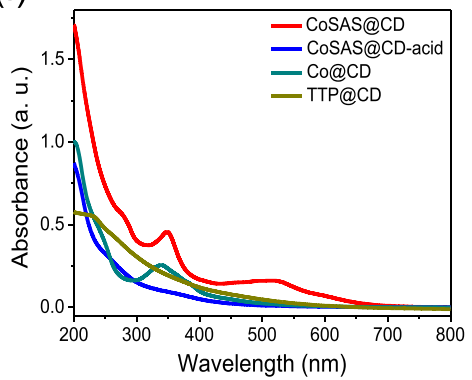

(i)

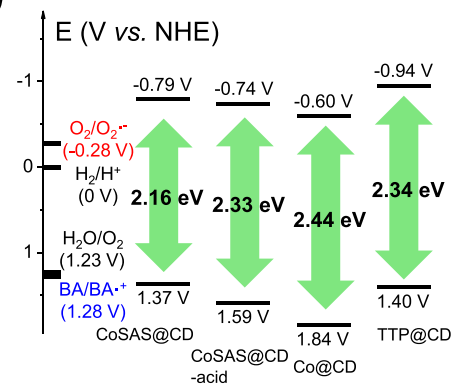

Figure 1. Morphologies, basic physical and optical properties of CoSAS@CD. (a) TEM image and size distribution (insert) of CoSAS@CD. (b) Representative HAADF-STEM image of CoSAS@CD. X-ray absorption near edge spectroscopy (XANES) profiles (c) and Fourier transform (FT extended X-ray fine structure (EXAFS) spectra (d) at the Co K-edge of CoSAS@CD, CoSAS@CD-acid, Co foil, CoO, CoOOH, and Co porphyrin (noted as Po). (e) Co 2p XPS spectrum of CoSAS@CD. (f) UV-vis spectra of CoSAS@CD, CoSAS@CD-acid, and VB12. (g) Steady-state fluorescence spectra of CoSAS@CD under various excitation wavelengths. (h) Fluorescence decay spectra of CoSAS@CD, CoSAS@CD-acid, Co@CD, and TTP@CD, excited at 400 nm. (i) VB and CB positions of CoSAS@CD, CoSAS@CD-acid, Co@CD TTP@CD, and other reactive substrates (BA is short for benzylamine).

most dots suggests that our CoSAS@CD primarily consist of 1-2 layers, which is comparable to most reported graphene quantum dots. $^{34,35}$ These results imply that the single cobalt atoms are majorly anchored on the surface of the quantum dot, which is facilely accessible to the substrates. We believe that the presence of abundance of exposed single Co on the surface of CoSAS@CD would make great contribution to the high catalytic efficiency.

The chemical state and the coordination environment of Co sites was determined by Co K-edge XANES and EXAFS. CoSAS@CD and CoSAS@CD-acid showed an absorption edge between $\mathrm{CoO}$ and $\mathrm{CoOOH}$, indicating the presence of both $\mathrm{Co}^{2+}$ and $\mathrm{Co}^{3+}$ (Figure 1c). As previously reported, cobalt in pristine VB12 generally appears as $\mathrm{Co}^{3+} \cdot 30,33$ The alteration of the oxidation state indicates that $\mathrm{VB} 12$ is partially reduced during the pyrolysis process at $250{ }^{\circ} \mathrm{C}$. In the Fourier transform (FT) $k^{3}$-weighted extended EXAFS spectra (Figure 1d), there is only one main peak at around $1.9 \AA$ in both CoSAS@CD and CoSAS@CD-acid, which is assigned to the $\mathrm{Co}-\mathrm{N} / \mathrm{C}$ first coordination shell as presence in the CoPo structure. The absence of a prominent $\mathrm{Co}-\mathrm{Co}$ peak at around
$2.5 \AA$ (and other high-shell peaks) in combination with the HAADF-STEM image would suggest that the cobalt species are atomically dispersed in CoSAS@CD.

The coordination number $(\mathrm{CN})$ of cobalt in the samples can be determined by XANES based on the characteristic peaks in the pre-edge absorption region from 7700 to $7720 \mathrm{eV}$. Typically, an absorption peak at around $7710 \mathrm{eV}$ is observed for $\mathrm{CoO}$, a six-coordinated octahedral structure. An absorption peak at around $7715 \mathrm{eV}$ is observed for $\mathrm{CoPo}$, with a fourcoordinated square-planar configuration typical for $\mathrm{Co}-\mathrm{N}_{4}$ structures. $^{33,36,37}$ CoSAS@CD and CoSAS@CD both displayed a strong absorption peak at around $7716 \mathrm{eV}$. Therefore, we concluded that the central Co in both is most probably in a four-coordination structure.

Fitting EXAFS allows the precise bond distance and $\mathrm{CN}$ to be determined, as shown in Figures S6-S7 and Table S1. The fitted CN for CoSAS@CD in the first shell is 4.1 with a distance of $1.91 \AA$ while for CoSAS@CD acid being slightly higher ( $\mathrm{CN} 4.3$ ) with a shorter metal-ligand bond length (1.90 ̊). Overall, those results indicate that the Co atom is anchored in the CQD with a square-planar $\mathrm{Co}-\mathrm{N}_{4}$ structure. 
The nature of Co and $\mathrm{N}$ binding was investigated with X-ray photoelectron spectroscopy (XPS). In the high-resolution $\mathrm{N}$ 1s spectrum (Figure S8), three peaks were found with a binding energy of 398.7, 400.0, $401.4 \mathrm{eV}$ attributed to pyridinic, pyrrolic, and graphitic $\mathrm{N}$, respectively. Highly active Co- $\mathrm{N}_{x}$ sites have previously been reported between single Co atoms and pyridinic $\mathrm{N}^{37-39}$ The high proportion of pyridinic $\mathrm{N}$ (66.7\% of the total N species) in CoSAS@CD is therefore beneficial for the immobilization of Co atoms and enhancement of catalytic capacity. The high-resolution Co $2 p$ spectrum (Figure 1e) displayed two peaks at the binding energy of 780.2 and $795.4 \mathrm{eV}$, corresponding to the $2 \mathrm{p}_{3 / 2}$ and $2 \mathrm{p}_{1 / 2}$, respectively. The interval of $15.2 \mathrm{eV}$ between those two peaks suggests the presence of $\mathrm{Co}^{3+} \cdot{ }^{40-42}$ In addition, the Co $2 \mathrm{p}_{3 / 2}$ peak and shake-up satellite peak around $784.8 \mathrm{eV}$ further suggests the presence of $\mathrm{Co}^{2+} \cdot{ }^{37}$ This suggests that the single $\mathrm{Co}$ atoms coordinate with $\mathrm{N} \mathrm{Co}^{2+}$ and $\mathrm{Co}^{3+}$ oxidation states, which is in accordance with those of XANES results.

The nitrogen and cobalt content in CoSAS@CD was determined by XPS to be 9.05 and 4.19 wt \% (Table S2). Co content was also determined via inductively coupled plasma optical emission spectrometry analysis, which produced a similar result $(3.27 \mathrm{wt} \%)$. The high concentration of $\mathrm{Co}$ in CoSAS@CD, close to that in VB12 (4.35 wt \%), indicates the efficiency of this low-temperature pyrolysis to retain Co atoms. For comparison, the XPS analysis of CoSAS@CD-acid, Co@ CD, and TTP@CD was also conducted (Figures S9-S11 and Table S2). Generally, CoSAS@CD-acid and TTP@CD carbon dot displayed an increased $\mathrm{O}$ and pyrrolic $\mathrm{N}$ concentration, resulting from the oxidative decomposition of carbon material during the carbon dot preparation. In addition, the $\mathrm{N} / \mathrm{C}$ ratio in CoSAS@CD-acid (0.12) is close to that in CoSAS@CD (0.14), indicating that the treatment with strong acid has slight influence on the $\mathrm{Co}-\mathrm{N}_{4}$ framework and the core of the CQD, while endowing the surface with abundant carboxylic groups. Co@CD showed a similar elemental composition to CoSAS@ CD.

Fourier transform infrared (FTIR) spectra (Figure S12) showed four characteristic peaks in VB12, band A (2134 $\left.\mathrm{cm}^{-1}\right), \mathrm{B}\left(1670 \mathrm{~cm}^{-1}\right), \mathrm{C}\left(1571 \mathrm{~cm}^{-1}\right)$, and D $\left(1545 \mathrm{~cm}^{-1}\right)$, which is corresponding to the vibrations of cyanide, acetamide, propionamide, and corrin ring, respectively. ${ }^{33,43}$ The cyanide peak is not present in spectra for CoSAS@CD and CoSAS@ $\mathrm{CD}$-acid, while others are diminished. This would indicate the decomposition of VB12. The increased absorption around $1625 \mathrm{~cm}^{-1}$ attributable to $\mathrm{C}=\mathrm{C}$ stretching vibration suggests the formation of the aromatic skeleton during the pyrolysis process.

The optical properties of CQDs were investigated by UVvis and photoluminescence (PL) spectra. CoSAS@CD displayed two absorption bands (around 348 and $525 \mathrm{~nm}$ ) assignable to $\pi-\pi^{*}$ transitions with an onset absorption of 650 $\mathrm{nm}$ (Figure 1f). Other carbon dots were dark brown in appearance, demonstrating broadened absorption, especially for CoSAS@CD-acid and TTP@CD. The presence of the carboxylic group on the surface of CoSAS@CD-acid, accompanying with a smaller particle size, caused a huge blue-shift in UV-Vis absorption when compared with that of CoSAS@CD. The higher intensity observed for CoSAS@CD compared to its counterparts is indicative of a higher quantity of surface traps, which may result in charge-transfer absorption. The luminescent property of CoSAS@CD was similar to previously reported carbon dots. A gradual bathochromic shift from 415 to $500 \mathrm{~nm}$ was observed with accompanying decreased fluorescence intensity when the excited wavelength increased from 300 to $420 \mathrm{~nm}$ (Figure $1 \mathrm{~g}$ ). This wavelengthdependent phenomenon is due to the presence of multiple fluorophores (surface traps and edge states) and the influence of the particle size distribution, a distinctive feature for CQDs. ${ }^{44-46}$ CoSAS@CD-acid and TTP@CD displayed wavelength-independent fluorescence with emission at around 435 and $510 \mathrm{~nm}$, respectively (Figures S13-S15).

The fluorescence lifetime for all the carbon dots was determined via time-resolved PL with values of 1.4, 2.2, 5.2, and 1.8 ns for CoSAS@CD, CoSAS@CD-acid, Co@CD, and TTP@CD, respectively (Figure 1h). The shortest lifetime for CoSAS@CD, combined with the dramatically decreased fluorescence intensity (Figure S16), indicates that the incorporation of a single Co atom could facilitate the dissociation of photoexcitons and promote the separation of electron-hole pairs. Improved photocarrier separation in CoSAS@CD was further confirmed by photocurrent and electrochemical impedance spectroscopy (EIS) analysis. As shown in Figure S17, CoSAS@CD produces the highest photocurrent response which was 2.6 times than TTP@CD, reflecting the most efficient light-induced electronic conductivity and electron-hole separation. In addition, the smallest arc radius in EIS suggests the lowest resistance for charge transfer in CoSAS@CD (Figure S18). Therefore, the combination of single cobalt atoms on carbon dot surfaces enhanced photocarrier generation and separation efficiency.

The optical band gap for all carbon dots was in the range of 2.16-2.44 eV, as derived from the Kubelka-Munk function (Figure S19). In addition, the conduction band (CB) position was determined from Mott-Schottky plots (Figure S20), and as a result, the valence band (VB) could then be calculated. CoSAS@CD had the narrowest band positions, but it is sufficient for oxygen species activation and benzylamine oxidation (1.28 V vs NHE). ${ }^{47-50}$ Besides the conductive band at $1.37 \mathrm{~V}$, the carbon dots were comparable to the previously reported polymer and carbon nitrile photocatalysts. ${ }^{49-52}$ All carbon dots demonstrated a high valence band, which suggests an excellent photocatalytic oxidative capacity.

A Lorentzian shape signal with a $\mathrm{g}$ factor of 2.20 was observed by electron spin resonance (ESR) and can be attributed to $\mathrm{Co}^{2+},{ }^{3}$ which is consistent with XANES and XPS analysis (Figure S21). Interestingly, while under the visible light irradiation, increased signal intensity is clearly observed, which may be on account of the light-induced transformation from the ESR-silent $\mathrm{Co}^{3+}$ species into $\mathrm{Co}^{2+}$.

The visible light-promoted photocatalytic activity of CoSAS@CD was determined for three different oxidative reactions. We first tested the photocatalytic oxygen evolution reaction (OER).$^{54-57}$ However, OER is not optimal because of the requirement of large overpotentials and sluggish kinetics. Here, using CoSAS@CD, a water oxidation activity of $90 \mu \mathrm{mol}$ $\mathrm{g}^{-1}$ was achieved in the first hour, using $\mathrm{AgNO}_{3}$ as an electrontrapping agent (Figure 2a). The amount of $\mathrm{N}_{2}$ was also detected with GC measurement as shown in Figure S22. An obviously lower amount of $\mathrm{N}_{2}$ was determined, suggesting that $\mathrm{O}_{2}$ was mainly from photocatalytic water splitting, while the contribution of air can be ignorable. The reduction in the oxygen evolution rate may be due to the formation of $\mathrm{Ag}$ nanoparticles through $\mathrm{Ag}^{+}$reduction, which may block the reaction sites. In order to prove the presence of $\operatorname{Ag}(0)$ 

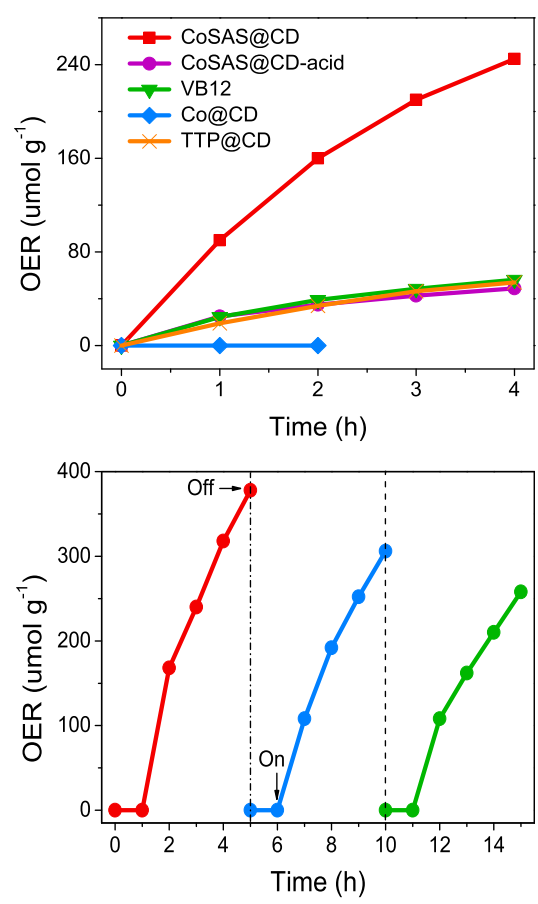

Figure 2. Photocatalytic $\mathrm{O}_{2}$ evolution. (a) Time course of produced $\mathrm{O}_{2}$ evolution for CoSAS@CD, CoSAS@CD-acid, VB12, Co@CD, and TTP@CD. (b) Time course of produced $\mathrm{O}_{2}$ with CoSAS@CD for three cycles.

nanoparticles on the surface of CoSAS@CD, XPS analysis was performed on the catalyst after the OER reaction. As shown in Figure S23a, the collected catalyst consists of C, N, O, Co, and $\mathrm{Ag}$. In the high-resolution Ag 3d XPS spectra (Figure S23b), the curve could be deconvoluted into two parts, which are ascribed to $\mathrm{Ag} 3 \mathrm{~d}_{3 / 2}$ and $\mathrm{Ag} 3 \mathrm{~d}_{5 / 2}$ orbits, respectively. The splitting of the $\mathrm{Ag} 3 \mathrm{~d}$ peaks at about $6 \mathrm{eV}$ indicates that the $\mathrm{Ag}$ element is mainly the presence as $\operatorname{Ag}(0) .{ }^{58,59}$ In addition, a deeper investigation of MNN Auger spectra was also conducted in order to further identify the chemical state of Ag (Figure S23c). According to the previous reports, ${ }^{60,61}$ the MNN Auger spectra consist of two difference transitions, that is, $\mathrm{M}_{4} \mathrm{~N}_{45} \mathrm{~N}_{45}$ and $\mathrm{M}_{5} \mathrm{~N}_{45} \mathrm{~N}_{45}$. As consequence, a modified Auger parameter $\left(\alpha^{\prime}\right)$ could be obtained which is the sum of binding energy of $\mathrm{Ag} 3 \mathrm{~d}_{5 / 2}$ and the kinetic energy of the $\mathrm{M}_{4} \mathrm{~N}_{45} \mathrm{~N}_{45}$ Auger peak. The value of $\alpha^{\prime}$ is mainly dependent on the Auger shift, and there is an obvious difference between $\mathrm{Ag}(0)(\sim 726 \mathrm{eV})$ and $\mathrm{Ag}^{+}(\sim 723 \mathrm{eV})$. In our case, the binding energy of $\mathrm{Ag} 3 \mathrm{~d}_{5 / 2}$ and the kinetic energy of the $\mathrm{M}_{4} \mathrm{~N}_{45} \mathrm{~N}_{45}$ Auger peak are 368.3 and $357.7 \mathrm{eV}$, respectively. Therefore, $\alpha^{\prime}$ of $\mathrm{Ag}$ is $726.0 \mathrm{eV}$, indicating that the chemical state of $\mathrm{Ag}$ on the collected catalyst is mainly $\operatorname{Ag}(0)$. The combination of high-resolution Ag 3d XPS and MNN Auger spectra offers a clear information that the surface of the catalyst is coated with $\operatorname{Ag}(0)$, which would prevent electron transfer from the photocatalyst to the surrounding electron sacrificial agent $\left(\mathrm{AgNO}_{3}\right)$, thus decreasing the OER evolution rate. In comparison, other carbon dots, such as CoSAS@CD-acid, TTP@CD, and VB12 demonstrated a significantly lower efficiency of 25,27 , and $24.5 \mu \mathrm{mol} \mathrm{g}{ }^{-1}$, respectively. The similar oxygen evolution rate between TTP@CD and CoSAS@CD-acid was probably because the enhancement in light absorption for TTP@CD was offset by its lower electron-hole separation efficiency as illuminated by photo- current and impedance spectra because the photocatalytic capacity was an integrated effect of light absorption, charge separation, and redox potentials. In addition, the oxygen evolution efficiency for VB12 was also comparable to that of porphyrin derivatives in the previous report. ${ }^{62}$ After $4 \mathrm{~h}$ of water oxidation, $245 \mu \mathrm{mol} \mathrm{\textrm {g } ^ { - 1 }}$ oxygen was produced by CoSAS@CD, which is more than 4 times that of other samples. This indicates that there is synergistic cooperation between the single Co atom and CQD. While all the carbon dots have a suitable valence band for oxygen evolution, the single Co atom anchored on the carbon dot may act as the active center for OER. ${ }^{63-65}$

An increase in oxygen evolution to $168 \mu \mathrm{mmol} \mathrm{g}^{-1}$ over the first hour occurred when the experiment was carried out in the presence of sodium iodate and electron acceptor (Figure $2 b$ ). After $4 \mathrm{~h}$, a total of $378 \mu \mathrm{mmol} \mathrm{g}{ }^{-1}$ of oxygen was obtained, comparable to current reports. ${ }^{54-57,63-65}$ No oxygen was collected in dark, suggesting the light-driven nature of the catalyst CoSAS@CD. The single atom photocatalyst CoSAS@ CD demonstrated excellent catalytic stability, with only a slight decrease in oxygen evolution activity over multiple cycles (Figure 2b), with $942 \mu \mathrm{mol} \mathrm{g}{ }^{-1}$ collected over three cycles.

Selective oxidation of benzylamine and its derivatives into imines is of great interest because of their important electrophilic intermediates in pharmaceuticals synthesis. ${ }^{12,47-50} \mathrm{We}$, therefore, tested the capacity of CoSAS@CD for the oxidation of benzylamine (Table 1). The CoSAS@CD photocatalyst under light irradiation produced solely $(E)-N$ benzyl-1-phenylmethanimine with a conversion of $83 \%$ (Table 1 entry 1 ). No product was detected in reactions undertaken in the dark or without the catalyst, (entries 2 and 3). As expected, a significantly lower conversion was obtained for CoSAS@CDacid, vb12, and TTP@CD (entry 4-6). Similar conversion between TTP@CD and TTP@CD-350 indicated the negligible influence of pyrolysis temperature on catalytic activity (entry 6-7). In addition, in order to investigate the specific role of photogenerated electron/hole pairs, different radical scavengers were added into the reaction mixture (entry 8-11). With the addition of $\mathrm{CuCl}_{2}$ as an electron scavenger, a reduced conversion of $23 \%$ was detected (entry 8 ). While $\mathrm{KI}$ is added as an electron scavenger, the conversion decreased to $34 \%$ (entry 9). This result indicated that photogenerated species make an important contribution to the reaction. Previously, singlet oxygen $\left({ }^{1} \mathrm{O}_{2}\right)$ and superoxide radical $\left(\mathrm{O}_{2}{ }^{\bullet-}\right)$ have been shown to play an important role in benzylamine oxidation. ${ }^{47-50}$ When $\mathrm{NaN}_{3}$ and benzoquinone were added as ${ }^{1} \mathrm{O}_{2}$ and $\mathrm{O}_{2}{ }^{\bullet-}$, respectively, a dramatically decreased reaction conversion was determined (entry 10-11), implying an essential role of both ${ }^{1} \mathrm{O}_{2}$ and $\mathrm{O}_{2}{ }^{\bullet-}$. Furthermore, the facilely generated ${ }^{1} \mathrm{O}_{2}$ and $\mathrm{O}_{2}{ }^{\bullet-}$ species by CoSAS@CD under visible light irradiation could be detected by electron paramagnetic resonance (EPR) measurements with 2,2,6,6-tetramethylpiperidine and 5,5-dimethyl-1pyrroline- $\mathrm{N}$-oxide as trapping agents (Figure S24). Based on the obtained results, a similar reaction as previously reported in the literature can be proposed. ${ }^{66,67}$ First, benzylamine may be oxidized by the photogenerated hole to form the corresponding cation radical. This radical can then react with two oxygen species to produce an imine intermediate eliminating $\mathrm{H}_{2} \mathrm{O}_{2}$. The imine intermediate can then further react with a second benzylamine molecule to produce the final product.

The versatility of CoSAS@CD was tested using various benzylamine derivatives. Both high reaction conversions and 
Table 1. Photocatalytic Oxidative Coupling of Benzylamines with CoSAS@CD under Visible Light and Corresponding Substrates Screening ${ }^{a}$

\begin{tabular}{|c|c|c|c|c|c|c|}
\hline Entry & Photocatalyst & Substrate & Product & Time (h) & $\begin{array}{l}\text { Conversion } \\
(\%)\end{array}$ & $\begin{array}{l}\text { Selectivity } \\
(\%)\end{array}$ \\
\hline 1 & CoSAS@CD & $\mathrm{R}=\mathrm{H}$ & $\mathrm{R}=\mathrm{H}$ & 12 & 83 & 99 \\
\hline $2^{\mathrm{b}}$ & - & $\mathrm{R}=\mathrm{H}$ & $\mathrm{R}=\mathrm{H}$ & 12 & - & - \\
\hline $3^{\mathrm{c}}$ & CoSAS@CD & $\mathrm{R}=\mathrm{H}$ & $\mathrm{R}=\mathrm{H}$ & 12 & - & - \\
\hline 4 & $\begin{array}{l}\text { CoSAS@CD- } \\
\text { acid }\end{array}$ & $\mathrm{R}=\mathrm{H}$ & $\mathrm{R}=\mathrm{H}$ & 12 & 58 & 99 \\
\hline 5 & VB12 & $\mathrm{R}=\mathrm{H}$ & $\mathrm{R}=\mathrm{H}$ & 12 & 20 & 99 \\
\hline 6 & TTP@CD & $\mathrm{R}=\mathrm{H}$ & $\mathrm{R}=\mathrm{H}$ & 12 & 31 & 99 \\
\hline 7 & TTP@CD-350 & $\mathrm{R}=\mathrm{H}$ & $\mathrm{R}=\mathrm{H}$ & 12 & 37 & 99 \\
\hline $8^{\mathrm{d}}$ & CoSAS@CD & $\mathrm{R}=\mathrm{H}$ & $\mathrm{R}=\mathrm{H}$ & 12 & 23 & 99 \\
\hline $9^{\mathrm{e}}$ & CoSAS@CD & $\mathrm{R}=\mathrm{H}$ & $\mathrm{R}=\mathrm{H}$ & 12 & 34 & 99 \\
\hline $10^{\mathrm{f}}$ & CoSAS@CD & $\mathrm{R}=\mathrm{H}$ & $\mathrm{R}=\mathrm{H}$ & 12 & 12 & 99 \\
\hline $11^{\mathrm{g}}$ & CoSAS@CD & $\mathrm{R}=\mathrm{H}$ & $\mathrm{R}=\mathrm{H}$ & 12 & 31 & 99 \\
\hline 12 & CoSAS@CD & $\mathrm{R}=p-\mathrm{CH}_{3}$ & $\mathrm{R}=p-\mathrm{CH}_{3}$ & 24 & 97 & 99 \\
\hline 13 & CoSAS@CD & $\mathrm{R}=p-\mathrm{OCH}$ & $\mathrm{R}=p-\mathrm{OCH}_{3}$ & 24 & 93 & 99 \\
\hline 14 & CoSAS@CD & $\mathrm{R}=o-\mathrm{OCH}$ & $\mathrm{R}=o-\mathrm{OCH}_{3}$ & 24 & 81 & 99 \\
\hline 15 & CoSAS@CD & $\mathrm{R}=p-\mathrm{Br}$ & $\mathrm{R}=p-\mathrm{Br}$ & 24 & 91 & 99 \\
\hline 16 & CoSAS@CD & $\mathrm{R}=p-\mathrm{F}$ & $\mathrm{R}=p-\mathrm{F}$ & 24 & 96 & 99 \\
\hline 17 & CoSAS@CD & $\mathrm{R}=p-\mathrm{Cl}$ & $\mathrm{R}=p-\mathrm{Cl}$ & 24 & 93 & 99 \\
\hline 18 & CoSAS@CD & $\mathrm{R}=p-\mathrm{CF}_{3}$ & $\mathrm{R}=p-\mathrm{CF}_{3}$ & 24 & 95 & 99 \\
\hline 19 & CoSAS@CD & & & 24 & 45 & 99 \\
\hline 20 & CoSAS@CD & & & 24 & 99 & 99 \\
\hline $21^{\mathrm{i}}$ & CoSAS@CD & & & 24 & 68 & 79 \\
\hline 22 & CoSAS@CD & & & 24 & 98 & 99 \\
\hline 23 & CoSAS@CD & $\widehat{\wedge}$ & - & 24 & - & - \\
\hline $24^{1}$ & CoSAS@CD & & & 24 & 97 & 80 \\
\hline $25^{\mathrm{m}}$ & CoSAS@CD & & & 24 & 95 & 81 \\
\hline
\end{tabular}

${ }^{a}$ Reaction conditions: substrate $(1 \mathrm{mmol})$, photocatalyst $(3 \mathrm{mg}), \mathrm{CH}_{3} \mathrm{CN}(3 \mathrm{~mL}), \mathrm{O}_{2}$ balloon, blue LED light. ${ }^{b}$ Without photocatalyst. ${ }^{c}$ In darkness. ${ }^{d} \mathrm{CuCl}_{2}$ was added as an electron scavenger. ${ }^{e} \mathrm{KI}$ was added as a hole scavenger. ${ }^{f} \mathrm{NaN}_{3}$ was added as a singlet oxygen scavenger. ${ }^{g}$ Benzoquinone was added as a superoxide radical scavenger. ${ }^{i}$ The major side products were $N$-(phenylmethylene)benzenemethanamine $(13 \%)$ and $\mathrm{N}$-isopropyl- $\mathrm{N}, \mathrm{N}$-dibenzylamine (8\%). ${ }^{j} 3$ equiv of heptylamine against benzylamine was added. The major side product was homo-coupling of benzylamine. ${ }_{3}$ equiv of heptylamine against (4-fluorophenyl)methanamine was added. The major side product was homo-coupling of (4fluorophenyl)methanamine.

excellent selectivity were achieved (entry 12-22). The catalyst displayed high functional group tolerance when using substituted benzylamines (entry 12-18). Interestingly, when the methoxy-substituted benzylamine is on the para position, higher conversion is observed compared to the ortho position, which is probably due to steric effects (entry 13-14). The reaction of secondary amines such as indoline and 1,2,3,4tetrahydroquinoline was investigated with varying success (entry 19-20). However, when $N$-benzylpropan-2-amine was used as the starting compound, limited selectivity (79\%) was achieved with two major side products formed, $\mathrm{N}$ (phenylmethylene)benzenemethanamine (13\%) and $\mathrm{N}$-isopropyl- $N, N$-dibenzylamine (8\%) (entry 21). Heterocyclic amines such as thiophen-2-ylmethanamine could also be coupled using this procedure (entry 22). In addition, the cross-coupling between benzylamine derivatives and heptylamine was investigated using our CoSAS@CD photocatalyst with desired cross-coupling products, N-heptyl-1-phenylmethanimine and 1-(4-fluorophenyl)- $N$-heptylmethanimine, being achieved with high reaction conversion and selectivity (entry 24-25). The oxidation coupling of heptylamine offered no conversion because of its high oxidation potential (entry 23). However, heptylamine could react with benzyliminium which was generated because of benzylamine oxidation, which would then give the final cross-coupling product $N$-heptyl-1phenylmethanimine. The substituted group, such as fluorine, had negligible influence on the cross-coupling reaction (entry 25). Therefore, the formation of cross-coupling products could not only support the proposed reaction mechanism but also enrich the distribution of our products. Lastly, it is worth 
mentioning that our CoSAS@CD photocatalyst demonstrated an excellent stability, as no decrease in both conversion and selectivity was observed during the whole four repeating cycles (Figure S25).

Given the high dispersibility of CQDs, we looked to test their performance in oxidative degradation of $\mathrm{RhB}$. As shown in Figure 3a, $\mathrm{RhB}$ is completely degraded within 10 min using
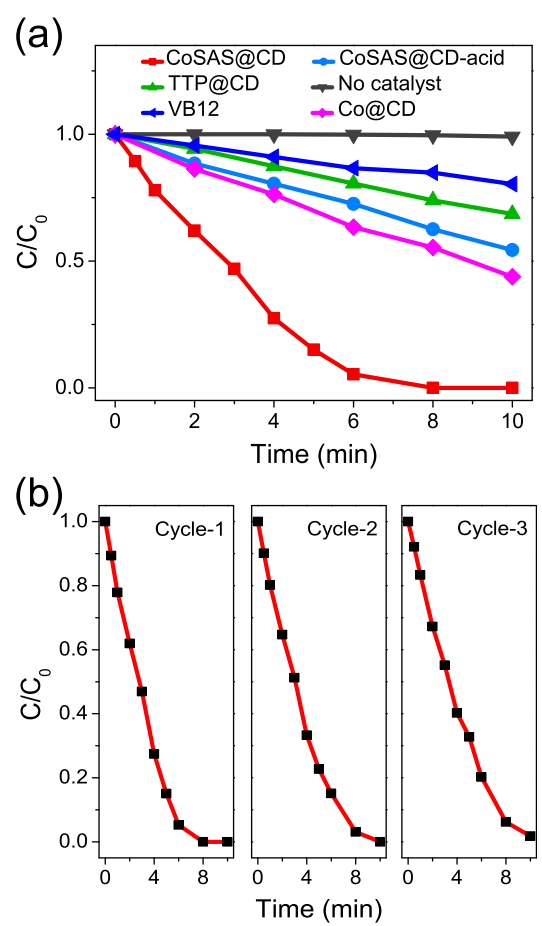

Figure 3. Photocatalytic efficiency of RhB degradation. (a) Photocatalytic degradation of RhB of CoASA@CD, CoASA@CD-acid, TTP@CD, Co@CD, and VB12. (b) Repeating experiment of photocatalytic RhB degradation with CoASA@CD.

CoSAS@CD as the photocatalyst. After 10 min of irradiation, significantly lower levels of degradation were observed for CoSAS@CD-acid (45.6\%), TTP@CD (31.5\%), VB12 (19.6\%), and Co@CD (51.8\%). Again, TTP@CD-350 displayed the same catalytic activity in $\mathrm{RhB}$ degradation compared to that of TTP@CD (Figure S26). To determine which reactive species $\left({ }^{1} \mathrm{O}_{2} ;{ }^{\bullet} \mathrm{O}_{2}^{-}\right.$; hydroxyl radical, ${ }^{\bullet} \mathrm{OH}$; photogenerated electrons, $\mathrm{e}^{-}$, and holes, $\mathrm{h}^{+}$) are involved in dye degradation, a series of control scavenger experiments was carried out (Figure S27). The introduction of scavengers decreased the dye degradation rate. This indicates that all the reactive species participated in the decomposition of $\mathrm{RhB}$. Moreover, when the experiment was conducted under an argon atmosphere, only $12.4 \% \mathrm{RhB}$ was decomposed, suggesting the essential role of oxygen. CoSAS@CD demonstrated excellent catalytic stability over multiple degradation cycles with no significant change to the degradation kinetics over three cycles (Figure $3 b$ ).

\section{CONCLUSIONS}

In summary, we have presented photocatalysts consisting of single cobalt atoms anchored onto CQDs. This new material shows outstanding optical properties, including strong visible light absorption, enhanced photocurrent response, and efficient charge separation. The incorporation of single cobalt atoms on
CQDs promoted the formation and transfer of photo-induced electron-hole pairs. The synergistic cooperation between the single cobalt atom and carbon dot endows the photocatalyst with an excellent catalytic efficiency for visible light-promoted oxidation reactions. We envision that this approach of anchoring single metal atoms onto carbon dots will be applicable for other metals. This could provide a new platform for atomically anchored metal photocatalysts.

\section{EXPERIMENTAL SECTION}

Chemicals. VB12 was purchased from Beijing J\&K Co., Ltd., China. Citric acid, ethylenediamine, $p$-tolualdehyde, pyrole, benzylamine, and $\mathrm{RhB}$ were obtained from Aladdin Co., China. Other organic solvents were purchased from Sinopharm Chemical Reagent Company. All chemicals were used without further purification.

Synthesis of Cobalt and Carbon Quantum Dot Hybrid Photocatalysts.Preparation of COSAS@CD and COSAS@CD-acid. To prepare VB12-based carbon material, $1 \mathrm{~g}$ of VB12 was placed in the center of the quartz boat and pyrolyzed in a tube furnace at 250 ${ }^{\circ} \mathrm{C}$ for $2 \mathrm{~h}$ at a heating rate of $5{ }^{\circ} \mathrm{C} \mathrm{min}^{-1}$ under a $\mathrm{N}_{2}$ atmosphere. The obtained carbon material was then hydrolyzed with $0.1 \mathrm{M} \mathrm{NaOH}$ solution at $80{ }^{\circ} \mathrm{C}$ for $24 \mathrm{~h}$. Finally, CoSAS@CD was obtained after filtration, dialysis for 3 days, and freeze-drying. For CoSAS@CD-acid, the same procedure was performed, while the carbon material was etched with a mixture of concentrated $\mathrm{H}_{2} \mathrm{SO}_{4}$ and $\mathrm{HNO}_{3}$ (v/v 3:1).

Preparation of Co@CD. Co@CDs was prepared using a typical hydrothermal method. Citric acid $(1.051 \mathrm{~g})$, ethylenediamine (335 $\mu \mathrm{L})$, and $\mathrm{Co}\left(\mathrm{NO}_{3}\right)_{2} \cdot 6 \mathrm{H}_{2} \mathrm{O}(0.260 \mathrm{~g})$ were dissolved in $10 \mathrm{~mL}$ of deionized water. Then, the formed solution was transferred into Teflon-lined autoclaves and treated at $300{ }^{\circ} \mathrm{C}$ for 5 h. Co@CDs was obtained after dialysis and freeze-drying treatment.

Preparation of TTP@CD. TTP was synthesized with a method as the previous report. ${ }^{68}$ Typically, a $500 \mathrm{~mL}$ flask was charged with $p$ tolualdehyde $(5 \mathrm{~g}, 82 \mathrm{mmol})$ and pyrrole $(5.5 \mathrm{~g}, 82 \mathrm{mmol})$ and 300 $\mathrm{mL}$ of propionic acid and heated until reflux overnight. After cooling down to room temperature, the solution was concentrated with a rotary evaporator. TTP was then obtained after extraction with methanol and hexane in a Soxhlet for $24 \mathrm{~h}$. Then, the synthesized TTP was calcined at $800{ }^{\circ} \mathrm{C}$ for $2 \mathrm{~h}$ under a $\mathrm{N}_{2}$ atmosphere to get TTP-based carbon material. Finally, TTP@CD was obtained after the treatment with a mixture of concentrated $\mathrm{H}_{2} \mathrm{SO}_{4}$ and $\mathrm{HNO}_{3}$ (v/v 3:1) at $80{ }^{\circ} \mathrm{C}$ for $24 \mathrm{~h}$, followed by dialysis and freeze-drying.

${ }^{1} \mathrm{H}$ NMR $\left(400 \mathrm{MHz}, \mathrm{CDCl}_{3}\right): \delta-2.71$ (s, $2 \mathrm{H}$, centro-pyrrolic $\mathrm{HSn}$ ), $2.75\left(\mathrm{~s}, 12 \mathrm{H}\right.$, meso-ArCH $\left.{ }_{3}\right), 7.61(\mathrm{~d}, J=7.6 \mathrm{~Hz}, 8 \mathrm{H}$, meso$\mathrm{ArH}$ ), 8.13 (d, $J=8.0 \mathrm{~Hz}, 8 \mathrm{H}$, meso-ArH), 8.90 (s, $8 \mathrm{H}, \beta$-pyrrolic $\mathrm{H}$ ).

General Procedures for Photocatalytic Oxidative Reactions. Photocatalytic oxygen evolution: typically, $50 \mathrm{mg}$ of photocatalyst was dispersed in $100 \mathrm{~mL}$ of deionized water under sonication. Then, 0.614 mmol La $\mathrm{O}_{3}(200 \mathrm{mg}$ ) and $1 \mathrm{mmol}$ sodium iodate (or silver nitrate) were added as the $\mathrm{pH}$ buffer agent and electron acceptor, respectively. After 3 times of evacuation, the reaction mixture was placed under the irradiation of $300 \mathrm{~W}$ Xe lamp with a filter to cut off UV part. The reaction solution was stabilized at room temperature by a flow of cooling water during the whole process. The generated gases were monitored in situ by the gas chromatograph with argon as the carrier gas.

Photocatalytic Benzylamine Oxidation. A flame-dried $10 \mathrm{~mL}$ vial with a magnetic stir bar was charged with benzylamine $(0.5 \mathrm{mmol})$, CoSAS@CD (3 mg), and acetonitrile $(3 \mathrm{~mL})$. The solution was first bubbled with $\mathrm{O}_{2}$ for $30 \mathrm{~min}$ and then placed under the irradiation of a blue light-emitting diode (LED) light $(460 \mathrm{~nm}, 100 \mathrm{~W})$ with $\mathrm{O}_{2}$ balloon. The conversion for the reaction was determined by GC-MS measurement. Other benzylamine derivatives with the same concentration were conducted using a similar approach and the corresponding conversion was analyzed by GC-MS.

Photocatalytic RhB Degradation. In a general procedure, an aqueous solution of $\mathrm{RhB}\left(10 \mathrm{mg} \mathrm{L}^{-1}\right)$ and the photocatalyst $(1 \mathrm{mg}$ $\mathrm{mL}^{-1}$ ) was stirred under dark with $\mathrm{O}_{2}$ bubbling for $30 \mathrm{~min}$ to reach adsorption-desorption equilibrium. After that, the mixture was 
illuminated with a blue LED light $(420 \mathrm{~nm}, 100 \mathrm{~W})$. The degradation $\mathrm{RhB}$ was recorded by UV-vis spectroscopy. In the repeating experiment, the same concentration of $\mathrm{RhB}$ was added after each reaction cycle without separating the photocatalyst. Moreover, in the control experiment, ammonium oxalate $\left(0.1 \mathrm{mmol} \mathrm{mL}^{-1}\right)$, $p$ benzoquinone $\left(0.1 \mathrm{mmol} \mathrm{mL}^{-1}\right)$, sodium azide $\left(0.1 \mathrm{mmol} \mathrm{mL}^{-1}\right)$, and isopropanol $\left(0.1 \mathrm{mmol} \mathrm{mL}^{-1}\right)$ were added as radical scavengers.

Characterizations. FTIR spectra were conducted on Thermo Fisher Scientific Nicolet iS10. UV-vis spectra Fluorescence spectra were carried out on Shimadzu UV-2600 and Hitachi F-7000, respectively. XRD was investigated on Rigaku MiniFlex 600 with a $\mathrm{Cu} \mathrm{K} \alpha$ X-ray beam. Atomic force microscopy(AFM) images were recorded using Bruker Bioscope system Multimode 8. Transmission electron microscopy (TEM) images were acquired by FEI Tecnai G2 F20 S-TWIN with an accelerating voltage of $200 \mathrm{kV}$. HAADF-STEM images were taken on JEOL JEM-2010 with a spherical aberration corrector working at $200 \mathrm{keV}$. XPS measurement was performed on Thermo Scientific ESCALAB 250Xi. EPR was carried out on JEOL JES-FA200. Gas chromatography-mass spectrometer (GC-MS) measurements were performed on a Thermo Finnigan TRACE200 GC-POLARIS Q Mass detector. Cyclic voltammetry (CV), photocurrent, EIS and Mott-Schottky were conducted on the IVIUM electrochemical workstation with a three-electrode-cell system: a glassy carbon electrode drop-casted with carbon materials as the working electrode, saturated calomel electrode (SCE) as the reference electrode, platinum electrode as the counter electrode, and $\mathrm{Bu}_{4} \mathrm{NPF}_{6}$ (0.1 $\mathrm{M}$ in acetonitrile) as the supporting electrolyte. For CV measurement, $\mathrm{Na}_{2} \mathrm{SO}_{4}(0.5 \mathrm{M}$ in aqueous solution) was used as the electrolyte solution. In the photocurrent analysis, the three-electrode cell was placed under the irradiation of blue LED light $(460 \mathrm{~nm}, 100$ W). Time-resolved PL spectra were monitored with a Olympus IX73 camera system. Excitation pulses at $400 \mathrm{~nm}$ were provided by frequency doubling the output of a commercial picosecond amplifier laser system.

$X$-ray Absorption Fine Structure Measurement and Data Analysis. The X-ray absorption fine structure (XAFS) spectra of Co K-edge were measured on BL14W1 beamline of Shanghai Synchrotron Radiation Facility (SSRF) operated at $3.5 \mathrm{GeV}$ with a constant current of $260 \mathrm{~mA}$. The XAFS data were collected at ambient temperature in the fluorescence excitation model using a 7element Ge solid-state detector. Athena and Artemis module implemented in the IFEFFIT software were employed to extract the data and fit the profiles. The energy was calibrated by the absorption edge of pure Co metal foil. For the X-ray absorption near edge structure (XANES) part, the experimental absorption coefficients as a function of energies $\mu(E)$ were obtained via background subtraction and normalization procedures and then displayed as "normalized absorption" in order to compare with those of standard samples, that is, Co foil $\left(\mathrm{Co}^{0}\right), \mathrm{CoO}\left(\mathrm{Co}^{2+}\right)$, and $\mathrm{CoOOH}\left(\mathrm{Co}^{3+}\right)$. For the extended XAFS (EXAFS) part, the Fourier transform (FT) data in $R$ space were calculated by employing the first shell approximation models for $\mathrm{Co}-\mathrm{N}$. The passive electron factors, $S_{0}^{2}$, were derived from fitting the experimental Co foil data and fixing the Co-Co CN to be 12 first, and then fixed for further analysis of the measured materials. Four parameters describing the electronic properties (e.g., correction to the photoelectron energy origin, $\left.E_{0}\right)$ and local structure environment including $\mathrm{CN}$, bond distance $(R)$, and Debye-Waller factor around the absorbing atoms were adjusted during the fitting process. The fitted ranges for $\mathrm{k}$ spaces were chosen to be $1-13 \AA^{-1}$ associated with an $\mathrm{R}$ space of $0.5-6.6 \AA$ ( $k^{3}$ weighted).

\section{ASSOCIATED CONTENT}

\section{s) Supporting Information}

The Supporting Information is available free of charge at https://pubs.acs.org/doi/10.1021/acs.chemmater.9b03708.

Additional experimental details and characterizations such as XPS, CV, EXAFS, EPR, fluorescence, FTIR, XRD, TEM, AFM, ${ }^{1} \mathrm{H}$ NMR, Mott-Schottky plot, and photocurrent and electrochemical impedances (PDF)
AUTHOR INFORMATION

\section{Corresponding Authors}

Kai. A. I. Zhang - Fudan University, Shanghai, China, and Max Planck Institute for Polymer Research, Mainz, Germany; 이이. orcidorg/0000-0003-0816-5718; Email: kai_zhang@fudan.edu.cn

Run Li - Hunan University, Changsha, China; Email: lirun@hnu.edu.cn

\section{Other Authors}

Qin Wang - Hunan University, Changsha, China

Jin Li - Hunan University, Changsha, China; (1) orcid.org/0000-0001-6530-197X

Xianjun Tu - Hunan University, Changsha, China Hongbo Liu - Hunan University, Changsha, China Miao Shu - Zhangjiang Laboratory, Shanghai, China Rui Si - Zhangjiang Laboratory, Shanghai, China Calum T. J. Ferguson - Max Planck Institute for Polymer Research, Mainz, Germany

Complete contact information is available at: https://pubs.acs.org/10.1021/acs.chemmater.9b03708

\section{Notes}

The authors declare no competing financial interest.

\section{ACKNOWLEDGMENTS}

This work was supported by the National Natural Science Foundation of China (21802081), Hunan Provincial Natural Science Foundation (2019JJ50085), and the Fundamental Research Funds for the Central Universities. The authors thank Mai He and Xiao Wang for the help of time-resolved PL measurement.

\section{REFERENCES}

(1) Hammarström, L. Accumulative Charge Separation for Solar Fuels Production: Coupling Light-Induced Single Electron Transfer to Multielectron Catalysis. Acc. Chem. Res. 2015, 48, 840-850.

(2) Zhang, M.; Wang, X. Two dimensional conjugated polymers with enhanced optical absorption and charge separation for photocatalytic hydrogen evolution. Energy Environ. Sci. 2014, 7, $1902-1906$

(3) Zhang, G.; Lan, Z.-A.; Wang, X. Surface engineering of graphitic carbon nitride polymers with cocatalysts for photocatalytic overall water splitting. Chem. Sci. 2017, 8, 5261-5274.

(4) Hutton, G. A. M.; Martindale, B. C. M.; Reisner, E. Carbon dots as photosensitisers for solar-driven catalysis. Chem. Soc. Rev. 2017, 46, 6111-6123.

(5) Han, M.; Zhu, S.; Lu, S.; Song, Y.; Feng, T.; Tao, S.; Liu, J.; Yang, B. Recent progress on the photocatalysis of carbon dots: Classification, mechanism and applications. Nano Today 2018, 19, 201-218.

(6) Yu, H.; Shi, R.; Zhao, Y.; Waterhouse, G. I. N.; Wu, L.-Z.; Tung, C.-H.; Zhang, T. Smart Utilization of Carbon Dots in Semiconductor Photocatalysis. Adv. Mater. 2016, 28, 9454-9477.

(7) Fernando, K. A. S.; Sahu, S.; Liu, Y.; Lewis, W. K.; Guliants, E. A.; Jafariyan, A.; Wang, P.; Bunker, C. E.; Sun, Y.-P. Carbon Quantum Dots and Applications in Photocatalytic Energy Conversion. ACS Appl. Mater. Interfaces 2015, 7, 8363-8376.

(8) Martindale, B. C. M.; Hutton, G. A. M.; Caputo, C. A.; Reisner, E. Solar Hydrogen Production Using Carbon Quantum Dots and a Molecular Nickel Catalyst. J. Am. Chem. Soc. 2015, 137, 6018-6025.

(9) Martindale, B. C. M.; Hutton, G. A. M.; Caputo, C. A.; Prantl, S.; Godin, R.; Durrant, J. R.; Reisner, E. Enhancing Light Absorption and Charge Transfer Efficiency in Carbon Dots through Graphitization 
and Core Nitrogen Doping. Angew. Chem., Int. Ed. 2017, 56, 64596463.

(10) Li, H.; Sun, C.; Ali, M.; Zhou, F.; Zhang, X.; MacFarlane, D. R. Sulfated Carbon Quantum Dots as Efficient Visible-Light Switchable Acid Catalysts for Room-Temperature Ring-Opening Reactions. Angew. Chem., Int. Ed. 2015, 54, 8420-8424.

(11) Pal, A.; Ghosh, I.; Sapra, S.; König, B. Quantum Dots in Visible-Light Photoredox Catalysis: Reductive Dehalogenations and C-H Arylation Reactions Using Aryl Bromides. Chem. Mater. 2017, 29, 5225-5231.

(12) Jeon, S.-J.; Kang, T.-W.; Ju, J.-M.; Kim, M.-J.; Park, J. H.; Raza, F.; Han, J.; Lee, H.-R.; Kim, J.-H. Modulating the Photocatalytic Activity of Graphene Quantum Dots via Atomic Tailoring for Highly Enhanced Photocatalysis under Visible Light. Adv. Funct. Mater. 2016, 26, 8211-8219.

(13) Li, H.; Liu, R.; Lian, S.; Liu, Y.; Huang, H.; Kang, Z. Nearinfrared light controlled photocatalytic activity of carbon quantum dots for highly selective oxidation reaction. Nanoscale 2013, 5, 32893297.

(14) Wu, W.; Zhang, Q.; Wang, R.; Zhao, Y.; Li, Z.; Ning, H.; Zhao, Q.; Wiederrecht, G. P.; Qiu, J.; Wu, M. Synergies between Unsaturated $\mathrm{Zn} / \mathrm{Cu}$ Doping Sites in Carbon Dots Provide New Pathways for Photocatalytic Oxidation. ACS Catal. 2017, 8, 747-753.

(15) Wang, J.; Gao, M.; Ho, G. W. Bidentate-complex-derived $\mathrm{TiO} 2 /$ carbon dot photocatalysts: in situ synthesis, versatile heterostructures, and enhanced $\mathrm{H} 2$ evolution. J. Mater. Chem. A 2014, 2, 5703-5709.

(16) Yang, P.; Zhao, J.; Wang, J.; Cao, B.; Li, L.; Zhu, Z. Construction of Z-scheme carbon nanodots/WO3 with highly enhanced photocatalytic hydrogen production. J. Mater. Chem. A 2015, 3, 8256-8259.

(17) Wang, Y.; Liu, X.; Liu, J.; Han, B.; Hu, X.; Yang, F.; Xu, Z.; Li, Y.; Jia, S.; Li, Z.; Zhao, Y. Carbon Quantum Dot Implanted Graphite Carbon Nitride Nanotubes: Excellent Charge Separation and Enhanced Photocatalytic Hydrogen Evolution. Angew. Chem., Int. Ed. 2018, 57, 5765-5771.

(18) Wang, A.; Li, J.; Zhang, T. Heterogeneous single-atom catalysis. Nat. Rev. Chem. 2018, 2, 65-81.

(19) Mitchell, S.; Vorobyeva, E.; Pérez-Ramírez, J. The Multifaceted Reactivity of Single-Atom Heterogeneous Catalysts. Angew. Chem., Int. Ed. 2018, 57, 15316-15329.

(20) Zhang, H.; Liu, G.; Shi, L.; Ye, J. Single-Atom Catalysts: Emerging Multifunctional Materials in Heterogeneous Catalysis. Adv. Energy Mater. 2017, 8, 1701343.

(21) Qiao, B.; Wang, A.; Yang, X.; Allard, L. F.; Jiang, Z.; Cui, Y.; Liu, J.; Li, J.; Zhang, T. Single-atom catalysis of $\mathrm{CO}$ oxidation using Pt1/FeOx. Nat. Chem. 2011, 3, 634-641.

(22) Chen, Z.; Vorobyeva, E.; Mitchell, S.; Fako, E.; Ortuño, M. A.; López, N.; Collins, S. M.; Midgley, P. A.; Richard, S.; Vilé, G.; PérezRamírez, J. A heterogeneous single-atom palladium catalyst surpassing homogeneous systems for Suzuki coupling. Nat. Nanotechnol. 2018, 13, 702-707.

(23) Zhu, C.; Fu, S.; Shi, Q.; Du, D.; Lin, Y. Single-Atom Electrocatalysts. Angew. Chem., Int. Ed. 2017, 56, 13944-13960.

(24) Su, J.; Ge, R.; Dong, Y.; Hao, F.; Chen, L. Recent progress in single-atom electrocatalysts: concept, synthesis, and applications in clean energy conversion. J. Mater. Chem. A 2018, 6, 14025-14042.

(25) An, S.; Zhang, G.; Wang, T.; Zhang, W.; Li, K.; Song, C.; Miller, J. T.; Miao, S.; Wang, J.; Guo, X. High-Density Ultra-small Clusters and Single-Atom Fe Sites Embedded in Graphitic Carbon Nitride (g-C3N4) for Highly Efficient Catalytic Advanced Oxidation Processes. ACS Nano 2018, 12, 9441-9450.

(26) Li, X.; Bi, W.; Zhang, L.; Tao, S.; Chu, W.; Zhang, Q.; Luo, Y.; Wu, C.; Xie, Y. Single-Atom Pt as Co-Catalyst for Enhanced Photocatalytic H2 Evolution. Adv. Mater. 2016, 28, 2427-2431.

(27) Liu, W.; Cao, L.; Cheng, W.; Cao, Y.; Liu, X.; Zhang, W.; Mou, X.; Jin, L.; Zheng, X.; Che, W.; Liu, Q.; Yao, T.; Wei, S. Single-Site Active Cobalt-Based Photocatalyst with a Long Carrier Lifetime for
Spontaneous Overall Water Splitting. Angew. Chem., Int. Ed. 2017, 56, 9312-9317.

(28) Huang, P.; Huang, J.; Pantovich, S. A.; Carl, A. D.; Fenton, T. G.; Caputo, C. A.; Grimm, R. L.; Frenkel, A. I.; Li, G. Selective CO2 Reduction Catalyzed by Single Cobalt Sites on Carbon Nitride under Visible-Light Irradiation. J. Am. Chem. Soc. 2018, 140, 16042-16047.

(29) Sun, T.; Zhao, S.; Chen, W.; Zhai, D.; Dong, J.; Wang, Y.; Zhang, S.; Han, A.; Gu, L.; Yu, R.; Wen, X.; Ren, H.; Xu, L.; Chen, C.; Peng, Q.; Wang, D.; Li, Y. Single-atomic cobalt sites embedded in hierarchically ordered porous nitrogen-doped carbon as a superior bifunctional electrocatalyst. Proc. Natl. Acad. Sci. U.S.A. 2018, 115, 12692-12697.

(30) Wan, G.; Lin, X.-M.; Wen, J.; Zhao, W.; Pan, L.; Tian, J.; Li, T.; Chen, H.; Shi, J. Tuning the Performance of Single-Atom Electrocatalysts: Support-Induced Structural Reconstruction. Chem. Mater. 2018, 30, 7494-7502.

(31) Liang, H.-W.; Wei, W.; Wu, Z.-S.; Feng, X.; Müllen, K. Mesoporous Metal-Nitrogen-Doped Carbon Electrocatalysts for Highly Efficient Oxygen Reduction Reaction. J. Am. Chem. Soc. 2013, 135, 16002-16005.

(32) Liang, H.-W.; Brüller, S.; Dong, R.; Zhang, J.; Feng, X.; Müllen, $\mathrm{K}$. Molecular metal-Nx centres in porous carbon for electrocatalytic hydrogen evolution. Nat. Commun. 2015, 6, 7992.

(33) Chang, S.-T.; Wang, C.-H.; Du, H.-Y.; Hsu, H.-C.; Kang, C.M.; Chen, C.-C.; Wu, J. C. S.; Yen, S.-C.; Huang, W.-F.; Chen, L.-C.; Lin, M. C.; Chen, K.-H. Vitalizing fuel cells with vitamins: pyrolyzed vitamin B12 as a non-precious catalyst for enhanced oxygen reduction reaction of polymer electrolyte fuel cells. Energy Environ. Sci. 2012, 5, 5305-5314.

(34) Jin, S. H.; Kim, D. H.; Jun, G. H.; Hong, S. H.; Jeon, S. Tuning the Photoluminescence of Graphene Quantum Dots through the Charge Transfer Effect of Functional Groups. ACS Nano 2013, 7, 1239-1245.

(35) Guo, C. X.; Dong, Y.; Yang, H. B.; Li, C. M. Graphene Quantum Dots as a Green Sensitizer to Functionalize ZnO Nanowire Arrays on F-Doped $\mathrm{SnO} 2$ Glass for Enhanced Photoelectrochemical Water Splitting. Adv. Energy Mater. 2013, 3, 997-1003.

(36) Scheuring, E. M.; Clavin, W.; Wirt, M. D.; Miller, L. M.; Fischetti, R. F.; Lu, Y.; Mahoney, N.; Xie, A.; Wu, J.-j.; Chance, M. R. Time-Resolved X-ray Absorption Spectroscopy of Photoreduced Base-off Cob(II)alamin Compared to the Co(II) Species in Clostridium thermoaceticum. J. Phys. Chem. 1996, 100, 3344-3348.

(37) Liu, W.; Zhang, L.; Yan, W.; Liu, X.; Yang, X.; Miao, S.; Wang, W.; Wang, A.; Zhang, T. Single-atom dispersed Co-N-C catalyst: structure identification and performance for hydrogenative coupling of nitroarenes. Chem. Sci. 2016, 7, 5758-5764.

(38) Han, Y.; Wang, Z.; Xu, R.; Zhang, W.; Chen, W.; Zheng, L.; Zhang, J.; Luo, J.; Wu, K.; Zhu, Y.; Chen, C.; Peng, Q.; Liu, Q.; Hu, P.; Wang, D.; Li, Y. Ordered Porous Nitrogen-Doped Carbon Matrix with Atomically Dispersed Cobalt Sites as an Efficient Catalyst for Dehydrogenation and Transfer Hydrogenation of N-Heterocycles. Angew. Chem., Int. Ed. 2018, 57, 11262-11266.

(39) Cao, Y.; Chen, S.; Luo, Q.; Yan, H.; Lin, Y.; Liu, W.; Cao, L.; Lu, J.; Yang, J.; Yao, T.; Wei, S. Atomic-Level Insight into Optimizing the Hydrogen Evolution Pathway over a Co1-N4 Single-Site Photocatalyst. Angew. Chem., Int. Ed. 2017, 56, 12191-12196.

(40) Zhao, Q.; Yao, W.; Huang, C.; Wu, Q.; Xu, Q. Effective and Durable Co Single Atomic Cocatalysts for Photocatalytic Hydrogen Production. ACS Appl. Mater. Interfaces 2017, 9, 42734-42741.

(41) Fei, H.; Dong, J.; Arellano-Jiménez, M. J.; Ye, G.; Dong Kim, N.; Samuel, E. L. G.; Peng, Z.; Zhu, Z.; Qin, F.; Bao, J.; Yacaman, M. J.; Ajayan, P. M.; Chen, D.; Tour, J. M. Atomic cobalt on nitrogendoped graphene for hydrogen generation. Nat. Commun. 2015, 6, 8668.

(42) Li, M.; Wu, S.; Yang, X.; Hu, J.; Peng, L.; Bai, L.; Huo, Q.; Guan, J. Highly efficient single atom cobalt catalyst for selective oxidation of alcohols. Appl. Catal., A 2017, 543, 61-66.

(43) Taraszka, K. S.; Chen, E.; Metzger, T.; Chance, M. R. Identification of structural markers for vitamin $\mathrm{B} 12$ and other 
corrinoid derivatives in solution using FTIR spectroscopy. Biochemistry 1991, 30, 1222-1227.

(44) Gan, Z.; Xu, H.; Hao, Y. Mechanism for excitation-dependent photoluminescence from graphene quantum dots and other graphene oxide derivates: consensus, debates and challenges. Nanoscale 2016, 8, 7794-7807.

(45) Baker, S. N.; Baker, G. A. Luminescent Carbon Nanodots: Emergent Nanolights. Angew. Chem., Int. Ed. 2010, 49, 6726-6744.

(46) Shamsipur, M.; Barati, A.; Karami, S. Long-wavelength, multicolor, and white-light emitting carbon-based dots: Achievements made, challenges remaining, and applications. Carbon 2017, 124, 429-472.

(47) Kang, N.; Park, J. H.; Ko, K. C.; Chun, J.; Kim, E.; Shin, H.-W.; Lee, S. M.; Kim, H. J.; Ahn, T. K.; Lee, J. Y.; Son, S. U. Tandem Synthesis of Photoactive Benzodifuran Moieties in the Formation of Microporous Organic Networks. Angew. Chem., Int. Ed. 2013, 52, 6228-6232.

(48) Li, H.; Yang, Y.; He, C.; Zeng, L.; Duan, C. Mixed-Ligand Metal-Organic Framework for Two-Photon Responsive Photocatalytic C-N and C-C Coupling Reactions. ACS Catal. 2019, 9, $422-430$.

(49) Su, F.; Mathew, S. C.; Möhlmann, L.; Antonietti, M.; Wang, X.; Blechert, S. Aerobic Oxidative Coupling of Amines by Carbon Nitride Photocatalysis with Visible Light. Angew. Chem., Int. Ed. 2011, 50, 657-660.

(50) Wang, Z. J.; Ghasimi, S.; Landfester, K.; Zhang, K. A. I. Molecular Structural Design of Conjugated Microporous Poly(Benzooxadiazole) Networks for Enhanced Photocatalytic Activity with Visible Light. Adv. Mater. 2015, 27, 6265-6270.

(51) Li, R.; Byun, J.; Huang, W.; Ayed, C.; Wang, L.; Zhang, K. A. I. Poly(benzothiadiazoles) and Their Derivatives as Heterogeneous Photocatalysts for Visible-Light-Driven Chemical Transformations. ACS Catal. 2018, 8, 4735-4750.

(52) Ghosh, S.; Kouamé, N. A.; Ramos, L.; Remita, S.; Dazzi, A.; Deniset-Besseau, A.; Beaunier, P.; Goubard, F.; Aubert, P.-H.; Remita, $\mathrm{H}$. Conducting polymer nanostructures for photocatalysis under visible light. Nat. Mater. 2015, 14, 505.

(53) Liu, W.; Zhang, L.; Yan, W.; Liu, X.; Yang, X.; Miao, S.; Wang, W.; Wang, A.; Zhang, T. Single-atom dispersed Co-N-C catalyst: structure identification and performance for hydrogenative coupling of nitroarenes. Chem. Sci. 2016, 7, 5758-5764.

(54) Rosen, J.; Hutchings, G. S.; Jiao, F. Ordered Mesoporous Cobalt Oxide as Highly Efficient Oxygen Evolution Catalyst. J. Am. Chem. Soc. 2013, 135, 4516-4521.

(55) Zhang, M.; Huang, Y.-L.; Wang, J.-W.; Lu, T.-B. A facile method for the synthesis of a porous cobalt oxide-carbon hybrid as a highly efficient water oxidation catalyst. J. Mater. Chem. A 2016, 4, 1819-1827.

(56) Lan, Z.-A.; Fang, Y.; Zhang, Y.; Wang, X. Photocatalytic Oxygen Evolution from Functional Triazine-Based Polymers with Tunable Band Structures. Angew. Chem., Int. Ed. 2018, 57, 470-474. (57) Yang, P.; Wang, L.; Zhuzhang, H.; Wang, R.; Titirici, M.-M.; Wang, $\mathrm{X}$. Photocarving nitrogen vacancies in a polymeric carbon nitride for metal-free oxygen synthesis. Appl. Catal., B 2019, 256, 117794.

(58) Yang, D.; Sun, Y.; Tong, Z.; Tian, Y.; Li, Y.; Jiang, Z. Synthesis of $\mathrm{Ag} / \mathrm{TiO} 2$ Nanotube Heterojunction with Improved Visible-Light Photocatalytic Performance Inspired by Bioadhesion. J. Phys. Chem. C 2015, 119, 5827-5835.

(59) Wang, D.; Zhou, Z.-H.; Yang, H.; Shen, K.-B.; Huang, Y.; Shen, S. Preparation of $\mathrm{TiO} 2$ loaded with crystalline nano Ag by a one-step low-temperature hydrothermal method. J. Mater. Chem. 2012, 22, 16306-16311.

(60) Cioffi, N.; Colaianni, L.; Pilolli, R.; Calvano, C. D.; Palmisano, F.; Zambonin, P. G. Silver nanofractals: electrochemical synthesis, XPS characterization and application in LDI-MS. Anal. Bioanal. Chem. 2009, 394, 1375-1383.
(61) NIST X-ray Photoelectron Spectroscopy Database; NIST Standard Reference Database Number 20; National Institute of Standards and Technology: Gaithersburg MD, 20899, 2000.

(62) Zhang, Z.; Zhu, Y.; Chen, X.; Zhang, H.; Wang, J. A FullSpectrum Metal-Free Porphyrin Supramolecular Photocatalyst for Dual Functions of Highly Efficient Hydrogen and Oxygen Evolution. Adv. Mater. 2019, 31, 1806626.

(63) Zhang, G.; Zang, S.; Lin, L.; Lan, Z.-A.; Li, G.; Wang, X. Ultrafine Cobalt Catalysts on Covalent Carbon Nitride Frameworks for Oxygenic Photosynthesis. ACS Appl. Mater. Interfaces 2016, 8, 2287-2296.

(64) Zhang, J.; Grzelczak, M.; Hou, Y.; Maeda, K.; Domen, K.; Fu, X.; Antonietti, M.; Wang, X. Photocatalytic oxidation of water by polymeric carbon nitride nanohybrids made of sustainable elements. Chem. Sci. 2012, 3, 443-446.

(65) Hong, D.; Jung, J.; Park, J.; Yamada, Y.; Suenobu, T.; Lee, Y.M.; Nam, W.; Fukuzumi, S. Water-soluble mononuclear cobalt complexes with organic ligands acting as precatalysts for efficient photocatalytic water oxidation. Energy Environ. Sci. 2012, 5, 76067616.

(66) Kang, N.; Park, J. H.; Ko, K. C.; Chun, J.; Kim, E.; Shin, H.-W.; Lee, S. M.; Kim, H. J.; Ahn, T. K.; Lee, J. Y.; Son, S. U. Tandem synthesis of photoactive benzodifuran moieties in the formation of microporous organic networks. Angew. Chem., Int. Ed. 2013, 52, 6228-6232.

(67) Wang, Z. J.; Ghasimi, S.; Landfester, K.; Zhang, K. A. I. Molecular Structural Design of Conjugated Microporous Poly(Benzooxadiazole) Networks for Enhanced Photocatalytic Activity with Visible Light. Adv. Mater. 2015, 27, 6265-6270.

(68) Wang, S.; Forsyth, C.; Langford, S. J. Supramolecular materials with robust and tunable channels constructed from tin(iv)porphyrin phenolates. CrystEngComm 2015, 17, 3060-3063. 